\title{
EXPERIMENTAL BEHAVIOUR OF NANO CONCRETE WITHNATURAL HYBRID FIBRE REINFORCEMENT (NHFR)
}

\author{
S.Sakthi Manikandan ${ }^{1}$, R.Sakthivel ${ }^{2}$ \\ ${ }^{1}$ Final year M.E Structural Engineering students, SVS College of Engineering, Coimbatore \\ ${ }^{2}$ Assistant Professor Department of Civil Engineering, SVS College of Engineering, Coimbatore
}

\begin{abstract}
The influence of Nano-Silica with Natural Hybrid fibers on various properties of concrete is obtained by replacing the cement with various percentages of Nano-Silica and adding of Natural Fibers. Nano-Silica is used as a partial replacement for cement in the range of 2\%,2.5\%,3\%,3.5\% \& 4\% for $M_{25}$ mix and Experiments were conducted for various percentages of the fibres such as $0.5 \%, 1 \%, 1.5 \%, 2 \% \& 2.5 \%$ by the weight of cement. Results indicate that the concrete, by using Nano-Silica powder, was able to increase its compressive strength and the tensile strength of the concrete was increased due to the addition of the fibres. The mechanical properties of the harden concrete were found by conducting tests such as compressive strength, flexural strength and split tensile strength for various percentage of the Nano-Silica With Natural Hybrid fibre content at the age of 7 and 28 days in the concrete.
\end{abstract}

Keywords: Nano Silica, Human Hair Fibre, Coir Fibre, Nano Concrete, Natural Fibre Reinforced Concrete.

\section{INTRODUCTION}

\subsection{Nano Concrete}

Concrete is the most common material used in the construction. It is a highly homogeneous material produced by mixture of finely powdered cement, aggregates of various sizes and water with inherent physical, chemical and mechanical properties. A reaction between the cement and water yields calcium silicate hydrate, which gives concrete strength and other mechanical properties of concrete as well as some by-products including calcium hydroxide.

Nano Technology applied to concrete includes the use of nanomaterial's like Nano silica, Nano fibres etc. By adding the Nanomaterial's, concrete composites with superior properties can be produced. Addition of Nano silica (NS) in concretes and mortars results in more efficient hydration of cement. Due to the pozzolanic activity, additional calcium silicate hydrates are formed to generate more strength and to reduce free calcium hydroxide. This also helps in reducing the cement requirement, NS improves the microstructure and reduces the water permeability of concrete thus making it more durable. Concretes with strengths as high as 100 MPa with high workability, anti-bleeding properties and short de-moulding time can be produced. Nano silica can be used as an additive to eco concrete mixtures.

\section{HYBRID FIBER REINFORCED CONCRETE} (HFRC)

Hybrid fiber reinforced concrete is the one in which more than one or two types of fibers are used as secondary reinforcement. In Fibre Reinforced Concrete (FRC), fibres can be effective in arresting cracks at both macro and micro levels. For an optimal response, different type of fibres may be suitably combined to produce Hybrid Fibre Reinforced Concrete (HFRC) .The use of optimized combinations of two or more types of fibres in the same concrete mixture can produce a composite with better engineering properties than that of individual fibres.

\subsection{Natural Fibres}

The usage of natural fibres in the concrete will serve to be eco-friendly and as the production of these fibres is natural there is no problem of pollution caused during theproduction of artificial fibres. The various natural fibres are Coconut, Sisal, Jute, Pineapple leaf,Date, Bamboo, Palm, Banana, Cotton, Human hair, Sugarcane fibres. The natural fibres which were used are coconut fibre and human hair fibre.

\subsection{Coconut Fibre}

The coconut fibre is mainly used for the purpose of controlling the crack and also for its excellent insulation against temperature. The coconut fibres are found in abundance and the coconut fibres obtained from coconut husk, belonging to the family of palm fibres, are agricultural waste products obtained in the processing of coconut oil, and are available in large quantities in the tropical regions of the world, most especially in Africa, Asia and southern America. The coconut fibres are tough and durable, resilient, spring back to shape even after constant use. 


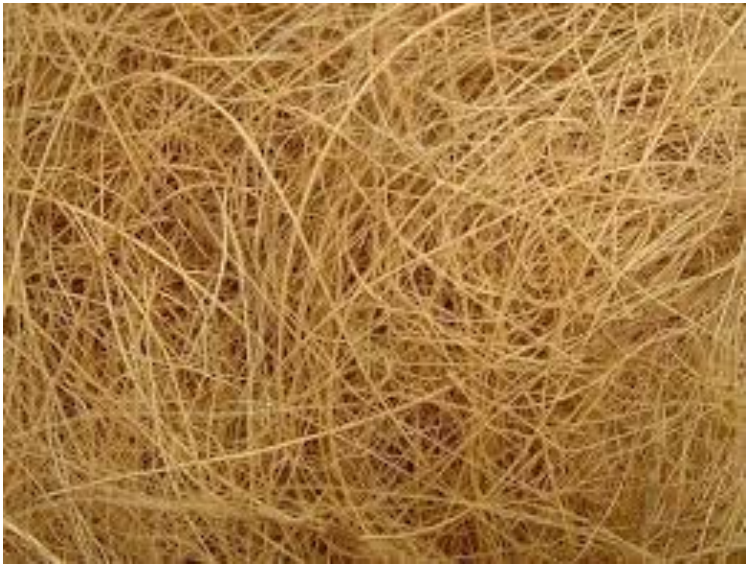

\subsection{Human Hair Fibre}

The human hair is strong in tension and it has strength equal to the copper wire of similar diameter. Hair, a nondegradable matter is creating an environmental problem so its use as a fibre reinforcing material can minimize the problem. It is also available in abundance and at a very low cost. It reinforces the mortar and prevents it from spalling. As hair is a non-degradable matter they can only really be disposed of by consigning them to landfill, and as such they are relatively environmentally unfriendly, thus the usage of hair as fibre reinforcement will reduce the landfill and it is eco-friendly.

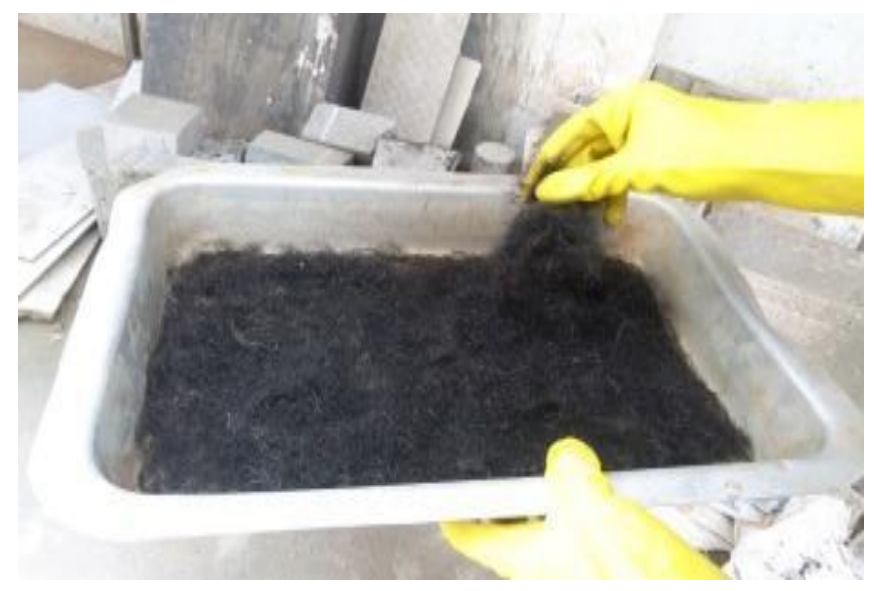

\subsection{Super Plasticizers}

A super plasticizer is used to improve the workability of fresh Nano concrete. The dosage of super plasticizer also has an effect on the compressive strength of concrete. It also gives good surface finish and reduces setting time. It is generally acknowledged that the slump loss of fresh concrete at the construction site is one of the principal reasons associated with problems related to the strength and durability of concrete.

To produce high workability concrete without loss of strength. To promote high early and ultimate strengths by taking advantage of water reduction whilst maintaining workability.
To produce high quality concrete of improved durability and permeability. At higher dosages, advantages can be taken of the retardation of initial setting time of concrete especially in large pours.

\section{OBJECTIVE}

$>$ The main objective of this project is to determine experimental investigation on behavior of Nano concrete With Natural Hybrid fiber reinforced concrete (NHFRC).

$>$ To compare the compressive strength, tensile strength and flexural strength of various specimens between control concrete and Nano concrete With Natural Hybrid Fiber Reinforcement Concrete.

$>$ The Nano materials such as Nano silica $\left(\mathrm{SiO}_{2}\right)$ of varying percentage are used And Natural Hybrid Fiber Reinforcement Concrete at 2\%, 2.5\%, 3\% \& 3.5\%,4\% in the concrete.

$>$ And the Natural Fibers like Coir and Human hair are used at $0.5 \%, 1 \%, 1.5 \%, 2 \%, 2.5 \%$ in concrete.

$>$ To compare the strengths of various specimens (cube, cylinder \& prism) between control concrete and Nano concrete With NHFRC (with various percentages).

\section{METHODOLOGY}

The main aim of this project is to determine the behaviour of Natural Hybrid Fibre Reinforced beam with Nano Concrete under cyclic loading. The following flow chart shows methodology of this project

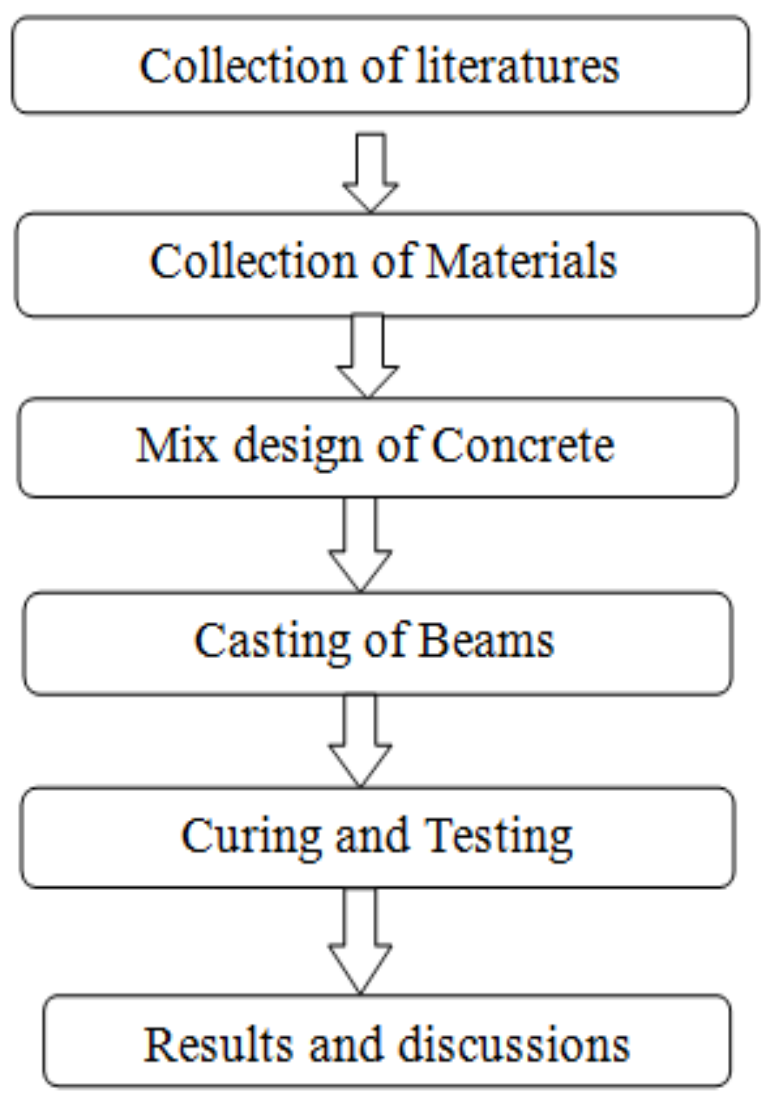




\section{TEST ON MATERIALS}

The preliminary tests were conducted on cement, fine aggregate, coarse aggregate, and the test results were obtained. Based on the results obtained the mix proportion for $\mathrm{M}_{25}$ concrete were done.

\begin{tabular}{|l|l|l|l|}
\hline Property & Cement & $\begin{array}{l}\text { Fine } \\
\text { Aggregate }\end{array}$ & $\begin{array}{l}\text { Coarse } \\
\text { Aggregate }\end{array}$ \\
\hline Fineness & $1 \%$ & 4.72 & 8.212 \\
\hline Consistency & $30 \%$ & - & - \\
\hline $\begin{array}{l}\text { Initial } \\
\text { setting time }\end{array}$ & $80 \mathrm{~min}$ & - & - \\
\hline $\begin{array}{l}\text { Specific } \\
\text { gravity }\end{array}$ & 3.18 & 2.62 & 2.78 \\
\hline
\end{tabular}

Mix proportion for $\mathrm{M}_{25}$ concrete

Cement

$=425.73 \mathrm{Kg} / \mathrm{m}^{3}$

$\begin{array}{ll}\text { Fine aggregate } & =649.498 \mathrm{Kg} / \mathrm{m}^{3} \\ \text { Coarse aggregate } & =1174.42 \mathrm{Kg} / \mathrm{m}^{3} \\ \text { Water cement ratio } & =0.45 \\ \text { Water content } & =191.58 \mathrm{Kg} / \mathrm{m}^{3} \\ \text { C: F.A: C.A } & =1: 1.52: 2.75\end{array}$

The mix proportion for $\mathrm{M}_{25}$ concrete is calculated using456:2000, IS 10262:2009. Super plasticizer CONPLAST SP430 is added to increase the workability of concrete.

\section{RESULTS FOR VARIOUS SPECIMENS}

\subsection{Compressive Strength Test}

The comparative results for compressive strength of concrete cubes between control specimen and NHFRC specimens are shown in the graph below.

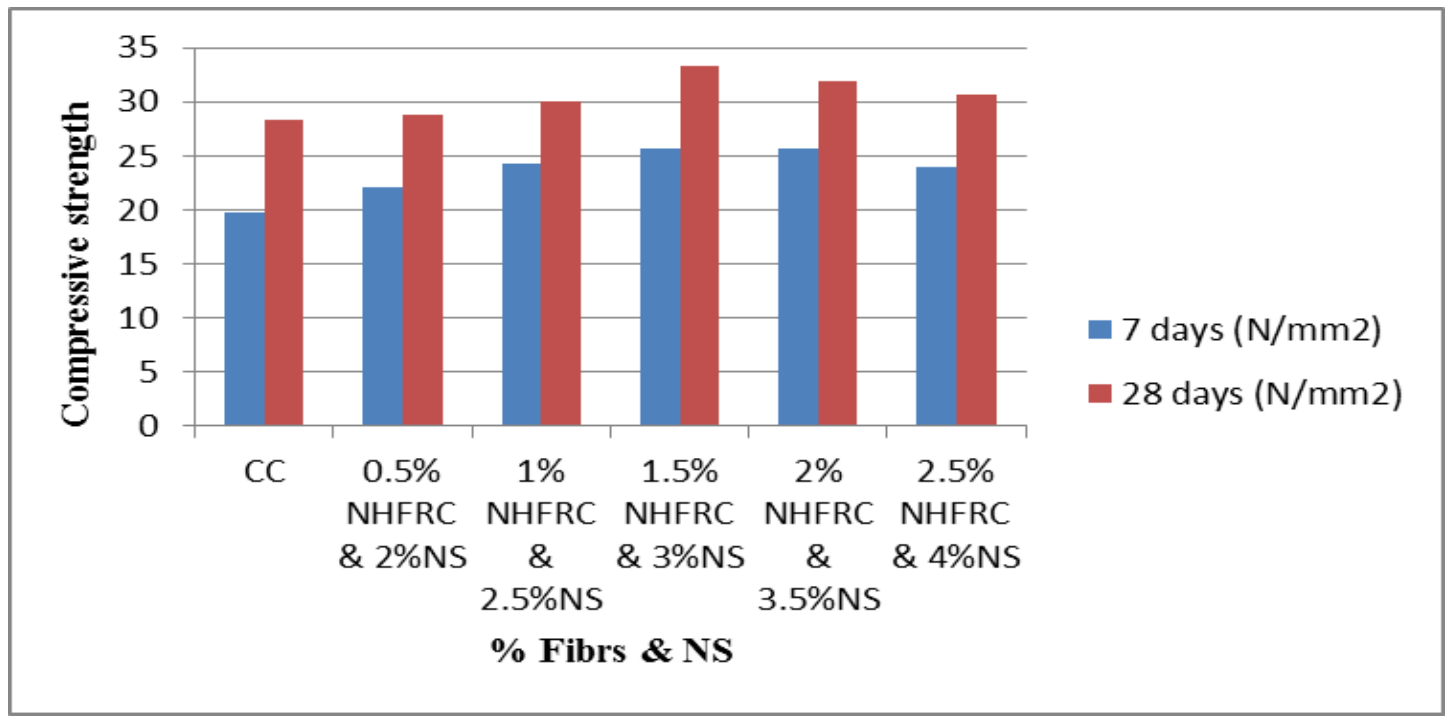

\section{Result}

The specimen with $1.5 \%$ NHFRC and 3\% NS showed maximum compressive strength of $33.23 \mathrm{~N} / \mathrm{mm}^{2}$.

\subsection{Split Tensile Strength Test}

The comparative results for split tensile strength of concrete cylinders between control specimen and NHFRC specimens are shown in graph below.

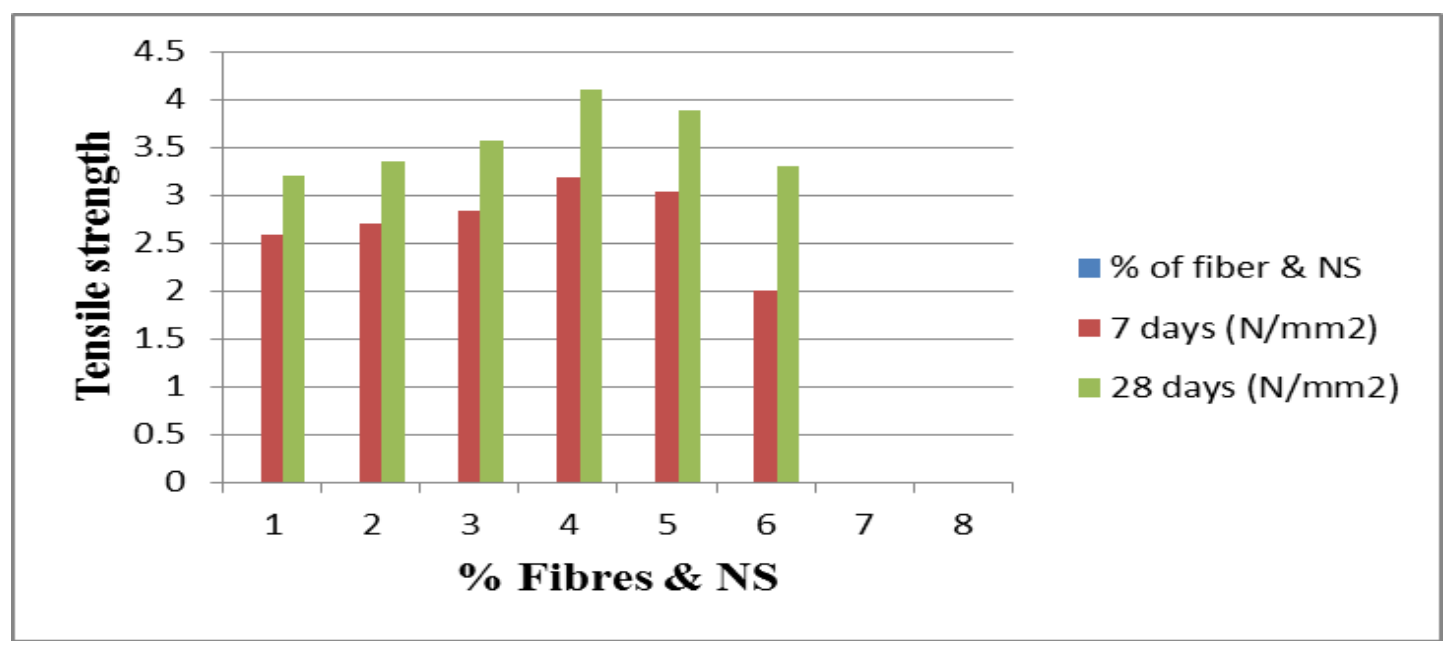




\section{Result}

The specimen with $1.5 \%$ NHFRC and 3\% NS showed maximum split tensile strength of $4.1 \mathrm{~N} / \mathrm{mm}^{2}$.

\subsection{Flexural Strength Test}

The comparative results for flexural strength of prism specimen between control specimen and NHFRC specimens are shown in graph below.

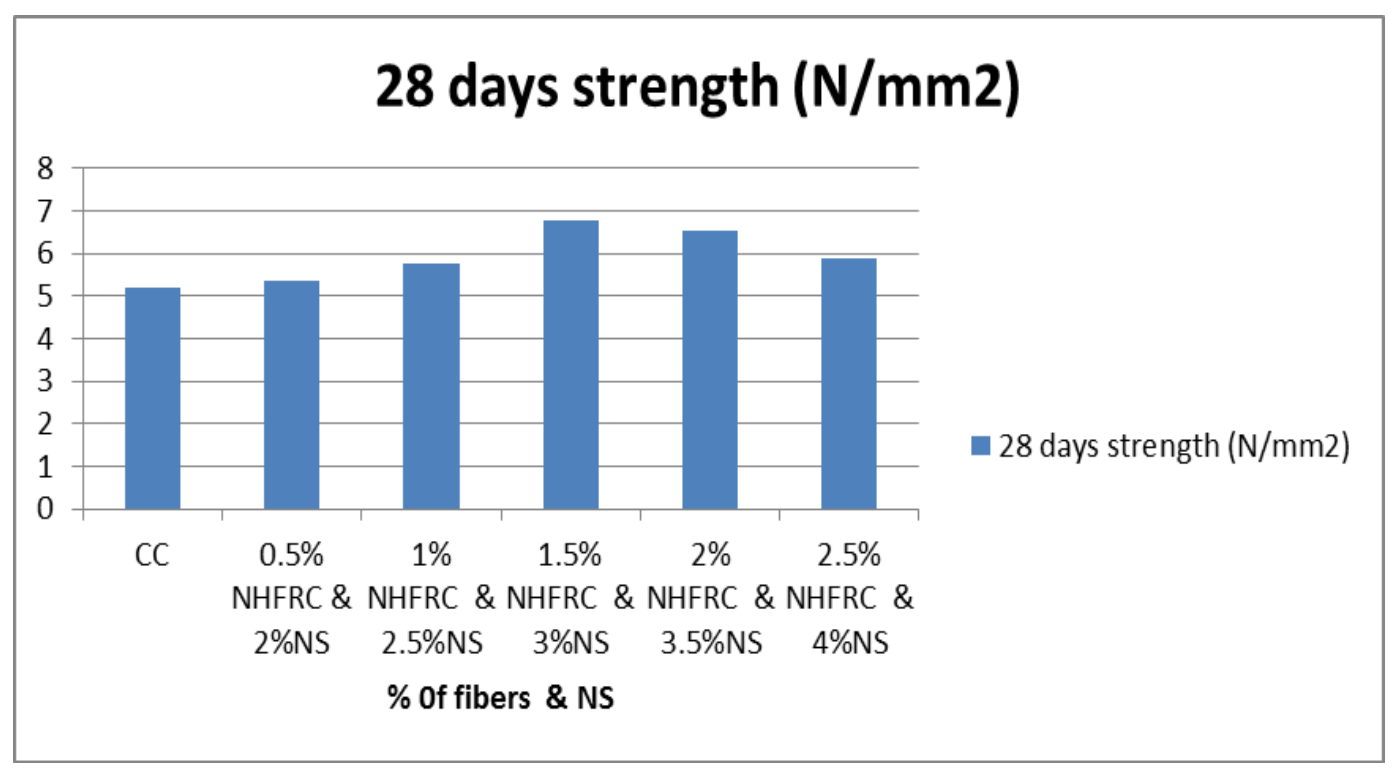

\section{Result}

The specimen with $1.5 \%$ NHFRC and 3\% NS showed maximum flexural strength of $6.79 \mathrm{~N} / \mathrm{mm}^{2}$.

\section{RESULT}

\subsection{Compression Test}

It was found that the compressive strength has been increasing with the increase in volume of Nano silica and Natural hybrid fibres up to $(3+1.5) \%$ of Nano silica(3\%) and Natural hybrid fibers(1.5\%). A decrease in strength was observed at $(3.5+2) \%$ of Nano Silica $(3.5 \%)$ and Natural hybrid fibres $(2 \%)$. The specimen with $(3+1.5) \%$ Of Nano silica $(3 \%)$ and Natural hybrid fibres(1.5\%) showed maximum compressive strength of $33.23 \mathrm{~N} / \mathrm{mm}^{2}$.

\subsection{Split Tension Test}

In this test, an increase in strength was observed up to $(3+1.5) \%$ of Nano Silica $(3 \%)$ and Natural hybrid fibres $(1.5 \%)$ and the specimen with $(3+1.5) \%$ of Nano Silica and Natural hybrid fibres showed maximum split tensile strength of $4.1 \mathrm{~N} / \mathrm{mm}^{2}$.

\subsection{Flexural Strength Test}

It was observed that the flexural strength of the concrete increases up to $(3+1.5) \%$ of Nano Silica $(3 \%)$ and Natural Hybrid Fibers $(1.5 \%)$ and it decreased gradually at $(3.5+2) \%$.The specimen with $(3+1.5) \%$ of Nano Silica and Natural hybrid fibres showed maximum flexural strength of $6.79 \mathrm{~N} / \mathrm{mm}^{2}$.

\section{CONCLUSION}

The utilization of natural hybrid fiber in concrete as a source of material which can be economic, eco-friendly, and recyclable. Natural hybrid fiber has highest cellulose content.The properties are suitable for its application on building and construction materials. The Nano silica used also gives workability and strength. The experimental result shows that Experimental behavior of natural hybrid fiber reinforced Nano concrete.

The initial and final setting times of cement mortar containing Nano-silica was found to decrease with increase in the replacement percentage. Use of Nano - silica in the concrete reduces the $\mathrm{CO}_{2}$ emission.

The Optimum Percentage is $1.5 \%$ of NHFRC(Natural Hybrid Fiber Reinforced Concrete And 3\% of NS(Nano Silica) in the concrete and It gives the Maximum Compressive strength, Split tensile Strength and Flexural Strength of the specimen.

And the Optimum Percentage Of NHFRC and NS can be used For the Construction of Concrete Building Which improves the Strength Of the Concrete.

\section{REFERENCES}

[1] Mix design as per IS 10262- 2009.

[2] Reinforcement Detailing as per IS 456-2000

[3] "Ductile detailing of reinforced concrete structures subjected to seismic forces" as per IS 13920:1993

[4] Dr. Claudia P. Ostertag, Professor, University of California,Engr. Joshua Blunt, Professor, University 
of California, 'Hybrid Fiber Reinforced Concrete For Use In Bridge Approach Slabs', ACI Structural 2006, title no 103-S58, pg no 551-558.

journal (technical paper) July-August

[5] Pitisukontasukkul, 'Hybrid Fibre Steel Reinforced Concrete Circular Plates Under Bending', The journal of KMITNB, vol 14, no 4, oct-dec 2009.

[6] YutianShaoand Amir Mirmiran, 'Experimental Investigation of Cyclic Behaviorof ConcreteFilled Fiber Reinforced Polymer Tubes', Journal of Composites for Construction, Vol. 9, No.3, June $1,2005$.

[7] 'Mechanical Properties Of Hybrid Steel Fibre Reinforced Concrete With Different Aspect Ratio', issue no 5(7): pg no 159- $\quad 166,2011$

[8] Agussalim,'Effect of compression reinforcement arrangement onductility of reinforced concrete beams , ACI structural journal, vol. 85-no.2, mach-april 1988.

[9] Varghese.P.C., “ Advanced Reinforced concrete design"

[10] M.S. Shetty, "Concrete Technology"

[11] S.K. Duggal , " earthquake resistant design of structure 